ANNUAL PROGRESS REPORT

for

January 16, 1988 through December 31, 1988

\title{
P.ESEARCH ON THE SEASONAL SNOW OF THE ARCTIC SLOPE
}

from

\author{
Professor Carl S. Benson \\ Geophysical Institute \\ University of Alaska \\ Fairbanks, Alaska 99775
}

\section{DISCLAIMER}

This report was prepared as an account of work sponsored by an agency of the United States Government. Neither the United States Government nor any agency thereof, nor any of their employees, makes any warranty, express or implied, or assumes any legal liability or responsiprocess disclosed, or represents that, or usefulness of any information, apparatus, product, or ence herein to any specific commercial product, not infringe privately owned rights. Refermanufacturer, or otherwise does not necessarily process, or service by trade name, trademark, mendation, or favoring by the United States Govetitute or imply its endorsement, recomand opinions of authors expressed herein do not necessarily agency thereof. The views United States Government or any agency thereof necessarily state or reflect those of the 
The original objectives of this research included a regional study of snow on the entire Arctic Slope. During the first year the scope was restricted to the $R_{4} D$ area. In the second and third years the primary focus was also on the $R_{4} D$ area, but measurements were made at Prudhoe Bay, Atqasuk and Wainwright to deter mine the flux of wind-blown snow on a wider scale. Additional broadening of scope was discussed at the San Diego R ${ }_{4} D$ meetings in April 1986 and 1987 and at the extrapolation workshop held at Penn State University in Spring 1987. The broadening of scope has also included detailed studies of (a) chemistry and (b) controls exerted by large-scale advection of air masses on the longwave, thermal IR, and radiation. The latter phenomena are critical in initiating snowmelt.

\section{SUMMARY OF RESEARCH IN PHASE I}

Topographic and Orthophoto Maps

The need for accurate topographic maps of the $R_{4} D$ research area was apparent in this project as well as for all other $R_{4} D$ projects. A mapping project was added to this project because of the investigator's experience with preparation of aerial photogrammetric maps. The details of establishing ground control, taking the vertical aerial photographs and preparing the photogrammetric products were presented in a report to the $R_{4} D$ investigators in April 1986. The products included:

1. Orthophoto negatives were prepared and orthophoto maps were made at the scales of $1: 6000$ and $1: 1000$.

2. Topographic contour maps were made of the overall area at scale of 1:6000 with $5 \mathrm{~m}$ contour interval. These contour maps were printed on top of the orthophoto maps. Two map sheets at this scale cover the overall area.

3. Topographic contour maps were made of the intensive study area at scale of 1:1000 with $1 \mathrm{~m}$ contour interval. These contour maps were printed on the $1: 1000$ scale orthophoto maps. Four map sheets at this scale cover the intensive area. 
The report identifies the USGS bench marks used to locate the map and to define a true North azimuth, and lists the coordinates of the 50 control points in the mapped area. The maps now have UTM grid coordinates on them.

Digitized Maps

A Digitized Elevation Model (DEM) was prepared by Dr. Gary Peterson of Penn State University for the area. The DEM combined with snow maps from this project and vegetation maps from Dr. Walker's project are proving useful (Evans, et al., 1987)

Aerial Photography

At the $R_{4} D$ meetings in San Diego during April 1986 it was decided that vertical aerial photographs, that could be printed to a scale of 1:500, were needed over the intensive study site. Two sets of photos were taken:

(a) Photos at scale 1:3000 for enlargement to scale of 1:500 over the intensive site.

(b) Photos at scale 1:9000 for enlargement to 1:1500 over an extended area within Map No. 2. of the 1:6000 series described above.

Their quality is excellent and they were available for use during the 1987 field season.

Research on Seasonal Snow During 1984, 1985, 1986, 1987, and 1988

The $1984-85,1985-86,1986-87$, and $1987-88$ seasonal snow was measured to determine its total quantity, its physical structure and its distribution as a function of wind and topography. Observations of meteorological parameters and snowpack characteristics during winter and spring have yielded information on the seasonal evolution of the snow in quantitative terms. A method of determining melt rates over large regions was developed and is being refined, progress was made on a model describing energy flux sources which control snow melting. A strong control is exerted by air mass advection on a broad scale. 
We are continuing to devote attention to the sources of energy and energy transfer mechanisms which control snow melt. The 1986 snow melt was two weeks later than the 1987 and 1985 meltouts. The delay was caused by advection of cold air from the Arctic Ocean. When it did get underway melting was very rapid and the snow pack disappeared in only half the time taken in 1985. However, the melt rates in 1987 and 1988 were exceptionally fast, especially 1988 which started earliest and melted fastest of all 4 years. The amount of the snowpack lost by evaporation varies from year to year but exceeds $40 \%$ over the entire area and varies from $10 \%$ to over $60 \%$ in individual test plots. In some ridge crest areas with shallow snow cover it probably exceeds $90 \%$. Our methods of determining melt rates over large areas are being refined and we are beginning to apply remote sensing, digital techniques to the problem. This will enable us to extrapolate to other areas on the Arctic Slope.

Distribution of snow across the $R_{4} D$ area was measured by combining several techniques. Snow depths, measured along selected traverses, are combined with pit studies to measure snow density, temperature and hardness profiles. In addition to providing water equivalent of the snow pack, the pit studies allow us to measure extreme snow types such as wind-slab and depth-hoar layers. Photographs were taken from control points at selected time intervals during each melt season. Three or four sets of oblique aerial photos were also taken during each melt season, except 1988 when the melt was too fast for us to get more than one set of vertical photos. The photography permitter, us to extrapolate detailed measurements made at points and on traverses to broad areas. By this means, maps of the maximum end-of-winter snow cover were made for 1985, 1986, and 1987. The map for 1988 is being completed now. The maps are being digitized as discussed above.

There was significant difference in strength of wind action from year to year the the $R_{4} D$ site, 1985 showed maximum wind slab formation. However, the 
direction of wind transport did not vary significantly. The sensitivity of snow distribution to topography is pronounced. Accumulation on lee slopes was about $65 \%$ more than on windward slopes, even though the slope angles were only 2 to 3 degrees. Some of the variability would not have been so clearly related to topography if our detailed topographic maps were not available.

Snow in the $R_{4} D$ area is transported by winds from the South. Southerly winds from the Brooks Range are felt in the Northern foothills for a variable distance across the entire East-West extent of the range. The predominant, and much stronger, winds that affect most of the Arctic Slope (all of the coastal plain) are from the East or West as mentioned above. We have devoted attention to the flux of windblown snow and to the boundary which separates the South flow from the prevailing East-West flows farther North. This is being done by making aircraft observations of drift directions and by measurements on the ground at Prudhoe Bay, Barrow, Wainwright, and Atqasuk. These observations have been combined with our flights to do oblique aerial photography over the $R_{4} D$ site.

The net winter flux of wind-blown snow can be expressed in unites of tonnes $(t=103 \mathrm{~kg})$ per meter normal to the wind $\left(t \mathrm{~m}^{-1}\right)$. On the coastal plain the average values are:

$70 \mathrm{tm}^{-1}$ from East winds

$35 \mathrm{tm}^{-1}$ from West winds

with negligible amounts from other wind directions. In the $R_{4} D$ area the dominant flux is from South winds with values of 10 to $20 \mathrm{tm}^{-1}$. West winds move more snow than East winds but the flux is only about $1 \mathrm{tm}^{-1}$. Although there is wide variability in the numerical values the basic distribution pattern remains remarkably constant from year to year.

A few vegetation types have clear correlations with snow depth. An excellent example is moist dwarf-shrub, fruticose-lichen tundra (cassiope tetragona or salix 
rotundifolia) which has about $53 \%$ of its occurrences in areas with $>30 \mathrm{~cm}$ of snow water equivalent although only about $1 \%$ of the total map area is in this snow class. This aspect of the program is being carried out cooperatively with $D$. Walker and $B$. Evans and makes use of the digitized map products (Evans, et al., 1987) Snow Chemistry

Being present for over half the year, arctic snow acts as a collection filter for many chemical species, yielding information on the time-integrated depositional processes. Chemical species in the arctic snow pack may be concentrated and deposited by numerous processes, including; incorporation of aerosol particles into clouds and subsequent precipitation, direct gas or aerosol deposition onto snow surfaces, wind transport of road or soil dust components, and biological processes. Since the arctic snow pack melts rapidly in the late spring, these chemical species will be added to arctic ecosystems suddenly, and may represent a large fraction of the total input to arctic lakes for some species. Due to the sensitive nature of arctic ecosystems, contributions which arise from anthropogenic activities need to be considered carefully.

Arctic snow chemistry has been considered by Barrie et al. [1985], Borys [1983], Weiss et al. [1978], Davidson et al [1987], and others. Some of these studies suggest that current pollution levels contribute significantly tot he concentration of numerous chemical species in arctic snow. For instance, Barrie used concentrations of $\mathrm{SO}_{4}{ }^{2}$ - and $\mathrm{NO}^{3}$ - levels found in ice cores obtained from the Canadian Arctic to show that the amount of anthropogenic constituents reaching the arctic has increased significantly in the 20th century.

Barrie reports pH's for snow of 4.5 to 5.0 in the Canadian Arctic, and attributes the acidity of this snow to contribution from acidic sulfate aerosols (i.e. "arctic haze"). Acidity in precipitation can arise from natural and anthropogenic sources (Charlson et al., 1987). The $\mathrm{CO}_{2}$ equilibrium point yields a pH of around 5.6 
depending on temperature; $\mathrm{pH}$ values between 5.0 and 5.6 in areas free of local contaminants often arise as a result of natural contributions; and $\mathrm{pH}^{\prime} \mathrm{s}$ of less than about 5.0 generally are believed to contain anthropogenic contributions. Wind transported soil and road dusts can significantly increase the $\mathrm{pH}$ of snow, due to species such as calcium, magnesium and iron carbonates, oxides, and hydroxides. In the vicinity of Prudhoe Bay, barium salts have been found to significantly increase the pH of ground water (U.S. Fish and Wildlife Service, 1987).

\section{$\underline{\text { Results }}$}

In March 1988, a sampling program was undertaken to collect snowpack samples along the Dalton Highway along a South t?, North traverse from central Alaska to the Arctic coast. Thirty-four samples were collected from seven different sites. Except at the MS117 site near Toolik Lake, (see below) all samples were collected at distances greater than $1 \mathrm{~km}$ from the highway so as to minimize contributions from wind transported road dust. Near the MS 117 site, 10 samples were collected at sites between $1 \mathrm{~m}$ and $4 \mathrm{~km}$ from the Dalton highway.

At the MS117 site a study of elution during snowmelt was done in 1987 and expanded in 1988. The 1987 study of stratigraphic layers showed a three fold increase in $\mathrm{SO}_{4}$ during deposition of surface hoar frost. In 1988 elution studies were done in the snow at Fairbanks to prepare for, (and have a basis for comparison), the MS117 stuudy. A total of 75 samples were collected during the melt season in the MS117 elution study.

Snowpack samples were collected directly into cleaned polyethylene bottles by digging a pit (with a clean plastic shovel) to the tundra surface and then scraping snow directly into the sampling bottles. The new polyethylene sampling bottles were soaked for 24 hours in $10 \% \mathrm{HCl}$, followed by two 12-hour soaks in distiiled, deionized water, and then rinsed with distilled, deionized water a minimum of 5 times. Analysis of lab and field blanks were consistently below the detection limits 
for $\mathrm{SO}_{4}{ }^{2}$ - and $\mathrm{NO}_{3}$ - Samples were kept frozen at less than $-10^{\circ} \mathrm{C}$ until chemical analyses were performed. All samples were analyzed for $\mathrm{pH}$, conductivity, and $\mathrm{Cl}$-, $\mathrm{SO}_{4}{ }^{2}$ - and $\mathrm{NO}_{3}$ - by ion chromatography in random order. Table one indicates analysis techniques and estimated detection limits.

Table 1

Chemical Analysis Techniques Used

\begin{tabular}{|l|l|c|c|}
\hline SPECIES & \multicolumn{1}{|c|}{ METHOD } & $\begin{array}{l}\text { (95\% confidence) } \\
\text { DETECTION LIMIT }\end{array}$ & REFERENCE \\
\hline $\mathrm{pH}$ & $\begin{array}{l}\text { Glass electrode with separate } \\
\text { reference electrode }\end{array}$ & -- & Galloway [1979] \\
\hline $\mathrm{Cl}-$ & $\begin{array}{l}\text { Suppressed column ion } \\
\text { chromatrography (scic) }\end{array}$ & $200 \mathrm{ppb}$ & [Tyree et al., 1979] \\
\hline $\mathrm{NO}_{3-}$ & scic & $100 \mathrm{ppb}$ & [Tyree et al., 1979] \\
\hline $\mathrm{SO}_{4} 2^{2-}$ & scic & $100 \mathrm{ppb}$ & [Tyree et al., 1979] \\
\hline
\end{tabular}

Results for the 34 samples are tabulated in appendix $A$. figures $1,2,3,4$, and 5 show plots of $\mathrm{pH}$, conductivity, $\mathrm{Cl}-, \mathrm{SO}_{4}{ }^{2-}$, and $\mathrm{NO}_{3}-$ vs $\mathrm{km}$ along the Dalton Highway ( $\mathrm{km} 0$ is at Livengood, Alaska).

Results from the perpendicular road traverse at the MS117 site (see appendix A) indicate that the oad is a significant source of increased $\mathrm{pH}$, conductivity, $\mathrm{Cl}$-, and $\mathrm{SO}_{4}{ }^{2-}$, but not of $\mathrm{NO}_{3}$-. These results also suggest that, at the $\mathrm{MS} 117$ site, road dust is not transported more than a few hundred meters.

\section{Discussion}

Snow collected in interior Alaska contains very low concentration of the chemical species measured, and is comparable to precipitation measured in other, remote unperturbed sites [Galloway, et al., 1982]. Snow on Alaska's North slope has significantly higher concentrations of all species measured. Analysis of variance (ANOVA) confirms that at the $95 \%$ confidence level, concentrations of all species 
measured are statistically different on the North slope as compared to interior Alaska. In other words, we can be $95 \%$ confident that the measured differences are due to real differences in the snow chemistry, rather than sampling or analysis variability.

The elevated concentrations observed in North slope snow may be a result of several different sources, including; wind transport of road dust, incorporation of "arctic haze" aerosol into cloud and snow particles, incorporation of sea salt particles into clocid and snow particles, and gas or aerosol emissions from the Prudhoe Bay complex. Data collected at the MS117 site indicates that transport of road dust does not exceed 200 meters. However, on the arctic coastal plain, the strength and prevalence of East-West winds and the low topographic relief may transport road dust further. Since $\mathrm{NO}_{3}$ - is not present at high concentrations in road dust, arctic haze, or sea salt, the high NOx emissions from the Prudhoe Bay facility are a likely source of the observed $\mathrm{NO}_{3}$ - in snow. Although little light is present during the dark arctic winter, oxidation mechanisms for $\mathrm{NO}$ and $\mathrm{NO}_{2}$ can still produce $\mathrm{HNO}_{3}$ either in the atmosphere or on the snow surface [Heikes and Thompson, 1983]. Graduate students Matthew Zukowski and Richard Honrath are participating in this under supervision by Dr. Daniel Jaffe.

\section{Meteorology}

Micro-meteorological data are being obtained at the $R_{4} D$ intensive study site by Graduate student Larry Hinzman and Professor Douglas Kane. These measurements are being used to determine heat and mass balance at the snow surface. In addition to this, we initiated a study in 1987 to assess the longwave radiation balance governed by large-scale advection of air masses. As a first step in this study, Dr. Sue Ann Bowling and the Principal Investigator determined the twice daily thickness of the 1000 to $500 \mathrm{mb}$ layer over the $R_{4} \mathrm{D}$ site. This was done by interpolation from the weather maps. The layer thickness is a convenient measure 
of the mean temperature in the lowest $5 \mathrm{~km}$ of the atmosphere. This in turn governs the amount of incoming longwave (thermal IRj radiation. The results were excellent and are summarized briefly.

Although the melting of snow at any particular site on the North Slope is normally complete within a week or less, the timing of snowmelt may vary by a month or more. Physically, energy can go into the latent heat of melting of snow if the energy flux toward the snow exceeds the black body flux outward from a surface at $0^{\circ} \mathrm{C}$, approximately 316 watts $/ \mathrm{m}^{2}$. This energy flux certainly includes (1) absorbed shortwave radiation, which is strictly limited by solar elevation angle (a known function of time of day and time of year), albedo (which has a feedback relationship with snowmelt), and the transparency of the atmosphere (which is determined largely by the humidity, temperature, and vertical motion of air advected into the area); (2) incoming longwave radiation (which is determined by the characteristics of the advected air with some possible modification by surface interactions such as heating of the lowermost layers by snow-free patches of ground); (3) sensible heat conducted downward from the atmosphere and (4) a negative contribution from heat conducted from the surface into the snowpack until the entire snowpack is at the melting point. Term (4) is transient.

Term (3) is often thought of as being the route by which advective heat reaches the surface, but this is probably incorrect -- transfer of sensible heat downward through an inversion is very inefficient, especially at the low surface wind speeds typical of the $R_{4} D$ research site. Regardless of whether variation in (3), (2) or (1) dominates, however, the year to year differences must come from differences in the characteristics of advected air.

As a small part of last year's study, we investigated the relationship between $1000-500 \mathrm{mb}$ thickness (a measure of mean temperature in the first $5 \mathrm{~km}$ of the atmosphere) and the timing of snowmelt for the first 3 years of this study. The 
results were astonishingly clear. The initiation of snowmelt coincided with thickness values over the site between 5360 and $5400 \mathrm{~m}$, with melt periods ranging from the beginning to the end of May. This was true even though the data used for the 1000 to $500 \mathrm{mb}$ thickness were scaled from interpolated weather maps, the short and longwave radiation balances would be expected to vary strongly with moisture and cloudiness, and sensible heat transfer would depend primarily on the temperature within the lowest few meters of the surface. In view of the potential usefulness of this result both in forecasting snowmelt and in modeling interaction between the atmosphere and snow cover, further studies are needed in several directions and are proposed below.

\section{Japanese Co-workers}

- Three researchers from the Institute of Low Temperature Science (Hokkaido University, Sapporo, Japan), joined us in our research during the 1988 field season: Drs. D. Kobayashi, Y. Kodama, and H. Motoyama. Their primary interest is in the relationship between water chemistry and runoff and the effect of snow cover on the time lag of runoff. They plan to join us again in 1989; all of their costs (travel, salaries and man-days at Toolik Lake) will be covered by a grant frc. $n$ the Japanese Ministry of Education. This represents a major asset to this project and the parallel ones under direction of D. Kane and K. Everett.

Products from This Research Include:

1. Orthophoto and topographic maps of the $R_{4} D$ research area: Two sheets at $1: 6000$ scale with $5 \mathrm{~m}$ contours, covering the entire $R_{4} D$ area. Four sheets at 1:1000 scale with $1 \mathrm{~m}$ contours, covering the intensive area (see text).

2. Liston, Glen E., (1986). Seasonal snowcover of the Foothills Region of Alaska's Arctic Slope: A survey of properties and processes. M.S. thesis, University of Alaska Fairbanks, Alaska 99775-0800.

3. Liston, G. E., G. J. Burger, J. M. Miller, and C. S. Benson, (1986) Snowmelt on Alaska's Arctic Slope as seen by LANDSAT. Cold Regions Hydrology Symposium, Fairbanks, Alaska, July 1986, Am. Water Resources Assoc. - Poster session. 
4. Evans, B. M., D. A. Walker, C. S. Benson, E. A. Nordstrand, and G. W. Peterson, (1988). Spacial interrelationships between terrain, snow distribution and vegetation patterns at an arctic foothills site in Alaska. Paper submitted to Holarctic Ecology.

5. Hinzman, L. D., D. L. Kane, C. S. Benson, ar,d K. R. Everett, (1988). Hydrologic and thermal properties of the arctic layer. Paper submitted to the Canadian Journal of Earth Sciences.

6. Kane, D. L., G. E. Liston, C. S. Benson, and K. R. Everett, (1988). Snow hydrology of a zero order arctic watershed. Paper submitted to the Canadian Journal of Earth Sciences.

7. Kane, D. L., L. D. Hinzman, K. R. Everett, and C. S. Benson, (1988). Hydrologicalecological interactions in an arctic watershed. Paper submitted to Holarctic. Ecology.

8. Zukowski, M. D.. (1988). A physical and chemical description of tundra snow from the foothills region of Alaska's Arctic Slope. M.S. thesis, University of Alaska Fairbanks, Alaska 99775-0800.

\section{PROPOSED RESEARCH FOR PHASE ॥}

Extension of research on seasonal snow will include analysis and synthesis of results from Phase I as well as continued field studies. These activities will be closely integrated, as before, with the other hydrologic field projects, directed by Everett and Kane, and with Walker's project on the distribution of vegetation. Snow chemistry studies and macro- as well as micro-meteorological studies are expanding to the extent that they are identified separately below. We will also benefit from the continued participation of our Japanese colleagues as mentioned above.

\section{Snow Distribution and Melt Processes}

Observations on the formation and evolution of the snowpack will be made as before. Comparisons will be made with the previous three winters, and new sites will be added along the haul road at the new meteorological stations established by Kane at Sagwon and Franklin Bluffs.

The effect of wind-blown snow in the Franklin Bluffs region was examined on satellite imagery obtained during the 1986 season (Liston, et al., 1986). We expect satellite and aerial photo images to assist in the task of determining the Northern 
DATE

FILMED

$12 / 1 / 92$ 
